\title{
Analyzing the Application of Functional Linguistics in Junior Middle School English Teaching
}

\author{
Yizhen Sun ${ }^{*}$ \\ Suzhou International Academy, BFSU, Suzhou, Jiangsu, 215000, China
}

\section{ARTICLE INFO}

Article history

Received: 13 April 2020

Revised: 20 April 2020

Accepted: 9 October 2020

Published Online: 16 October 2020

Keywords:

Junior middle school English

English teaching

Functional language

Application

\begin{abstract}
Based on the application of functional linguistics in junior middle school English teaching, this paper first illustrates the concepts of systematic grammar and functional grammar. Secondly, according to the application of functional grammar in reading, in translation and in writing, it is concluded that applied linguistics has an important role in promoting junior middle school English teaching, which comprehensively illustrates the importance of functional linguistics in junior middle school English teaching. Functional linguistics is of great significance to instruct junior middle school teaching. This paper explores the definition of functional linguistics and the linguistic patterns of functional linguistics.
\end{abstract}

\section{Analyzing through Systematic Functional Grammar}

A $\mathrm{t}$ present, China advocates reforming in teaching methods of junior middle school English, but the teaching method adopted does not meet the needs of social development. Affected by traditional teaching methods, traditional teaching methods mainly use grammar, words, and phonetics as the main teaching content, but they do not cultivate students' ability in language use, which has led to a lack of discourse awareness. Therefore, school leaders and related persons should be aware of this problem. Teachers should use functional linguistics for junior middle school English teaching so as to improve the quality of teaching in an all-round way.

\subsection{Systematic Grammar}

This paper studies by systematic functional grammar. Halliday believes that systematic grammar's structure represents a deep syntagmatic relation, and the system represents a deep paradigmatic relation. These two relations constitute the basic deep relation in language. However, in the operation of the system network, these two relations have no dependencies, and the two are coexisting relationships. The application of systematic grammar can guide students to establish the correct value orientation. To a certain extent, it can help students build a complete

*Corresponding Author:

Yizhen Sun,

Suzhou International Academy, BFSU, Suzhou, Jiangsu, 215000, China;

E-mail: sunpcy@163.com. 
grammar and knowledge framework, thereby fully grasping the points of knowledge. For example, when learning noun clauses, students do not grasp the meaning of noun clauses, so they are always confused about attributive clauses and appositive clauses. The main reason is that students do not have basic knowledge. The meaning potential of each clause is different. Only by fully grasping the meaning of each clause can students fully distinguish the various clauses. Each level of language is closely related to the whole, so in the process of learning grammar, a systematic study of each level is required.

\subsection{Functional Grammar}

Halliday believes that language has three metafunctions, including ideational metafunction, interpersonal metafunction, and textual metafunction. The ideational function can help students grasp verbs and tenses of English. In terms of the transitivity system, it mainly has four processes, such as material process, mental process, relational process and verbal process. Progressive tense won't be used for the verbs expressed in mental or relational processes. Tense or voice will be used for the verbs expressed material or verbal processes. The interpersonal function can help students master grammar and improve students' logical thinking ability. At the same time, it also can help students accurately grasp and understand the meaning of English mood expressions and modal verbs. At the same time, it is also necessary to divide the user's language process expression into "information taking" and "goods\&services exchanging". Meanwhile, there are declarative and imperative moods in the process of expression, and they all have a clear theoretical framework to help students fully understand the concept of English mood. Regarding the analysis of traditional teaching concepts, mood is a new form of predicate verbs, including declarative sentences, interrogative sentences and others. However, the traditional teaching mode makes students' learning goals more and more blurred. The discourse function is anaphora in English grammar, with omissions and substitutions.

As explained above, the differences between systematic grammar and traditional grammar can be drawn. Systematic grammar mainly treats language as the source of meaning, while traditional grammar treats language as a rule, and then forms a system for description. Systematic functional grammar usually uses text as the main tool to obtain information, while traditional grammar uses sentence as the basic unit to obtain information. This shows that grammar cannot learn by rote. The traditional grammatical applications can no longer meet the development needs of modern society. Therefore, it is necessary to combine form and meaning for students to fully grasp the grammar.

\section{The Application of Systematic Functional Linguistics in Junior Middle English Teaching}

At present, more and more linguists and language teaching working groups are actively studying the English teaching situation in junior middle schools and discussing the effective ways of English teaching. Functional grammar is one of them.

\subsection{Functional Grammar in Reading}

In junior middle school English teaching, students need to improve their reading ability, master reading skills, and to a certain extent, improve the overall level of English. At the same time, students can correctly grasp and understand the language difficulty. English reading involves a lot, and many articles have a wide range of topics. Therefore, how to use is very important. At present, in the process of English teaching, teachers should optimize teaching methods, aiming at training students to master reading methods. Reading is from top to bottom, and students need to read in the overall order of the article. During this process, students also need to reflect on themselves and find their own way of reading. One of these methods is the searching reading. First of all, before reading, students should read according to the questions for it can save time. Students do not need to read sentence by sentence, just need to find the information to solve the problem in the article. However, in the actual application process, this method is mainly used in long articles, or students with poor grammar foundations.

\subsection{Functional Grammar in Translation}

At present, the improvement of the social and economic structure requires a large number of talents. Particularly, the requirement for English translation ability is getting higher and higher. Therefore, the English translation ability of students should be strengthened, as long as they have sufficient knowledge of vocabulary and grammar, they can solve problems in translation. First of all, teachers need to master the main purpose of English teaching, and they can do conversion between languages, specifically between English and Chinese. It is not possible to seek a single equivalent translation between English and Chinese. After all, translation involves many factors. Secondly, to a certain extent, the conceptual elements in functional grammar can improve students' ability in translation and language organization ability, and help student's better master basic knowledge. In systematic functional linguistics, the ide- 
ational function is mainly realized through transitivity and voice. Transitivity is a language system that can divide what people see and hear in reality into many processes. The division of these processes can help students find logical relationships in translation, and at the same time, find similar meanings to the original text in the corresponding equivalence range. Functional linguistics is mainly to help students master interpersonal language functions and improve their reading ability. On this basis, students can participate in the context of the situation in person so as to deeply understand the meaning and ideas expressed in the original text.

\subsection{Functional Grammar in Writing}

To master the four basic skills, including listening, speaking, reading and writing is important for learning English well. Among them, writing is the best reflection of students 'actual English level, and it is also a comprehensive reflection of learners' English level and thinking ability. How to improve English writing ability has become a problem for English teachers and students.

The Textual function is a good embodiment of interpersonal function and ideational function. It mainly observes the speaker's attitude for emotion and various social roles are closely connected. During this period, the meaning of the text can be realized by the improvement of the main structure and information. At the same time, students are unaware of the textual function in reading and writing. It can comprehensively improve (students') English writing from the perspective of systematic functional grammar. In the process of writing, choosing an appropriate language expression can achieve the real purpose of writing practice. However, the cultivation of writing ability by traditional ways only pays attention to students' grammatical knowledge and vocabulary but ignores the variability of language. The application of systematic functional grammar in English teaching can effectively help students master the whole article, stimulate them to use language creatively, and improve their comprehensive ability in English application ${ }^{[1]}$.

\section{The Important Role of Applied Linguistics in Junior Middle School English Teaching}

\subsection{Inspiration from Motivation Theory}

As part of linguistics, it is necessary to improve the theoretical system of applied linguistics, and use it as a supporting point, focusing on different aspects of language teaching including the specific content of language learning and teaching, learning strategies and motivations.
Learning motivation is the main motivation for students to learn, including internal motivation and external motivation. To some extent, the external motivation will be affected by external factors while the internal motivation is the self-development needs of students. After a lot of teaching feedback, learning motivation can increase students' learning activities. Therefore, good learning opportunities can guarantee students' learning efficiency and quality. The effective use of motivation theory ${ }^{[2]}$ can be comprehensively reflected in the following points:

(1) Stimulate students to learn based on the actual situation so that teachers can directly see the needs of students. The main purpose of students learning English is to meet the requirements of social development and become the pillar of the country. Therefore, the teaching goal can go straight to the topic, and the teacher can tell the students what knowledge should be studied and what will be tested. For instance, when the difficulty of English translation increases, teachers can supplement practical skills related to translation in teaching so as to stimulate students' motivation to learn.

(2) Affected by the length of classroom teaching, some teachers will arrange the whole course properly. Some teachers in the whole class are briefly presenting the knowledge points, but they ignore the students 'independent learning practice, resulting in a thin learning atmosphere and a single learning mode. To a certain extent, this approach may affect students' learning quality and teaching efficiency. In fact, in classroom teaching, teachers can use multimedia methods to introduce situational presentations to promote students 'motivation to learn and enable students to participate actively, thereby comprehensively improving teaching efficiency ${ }^{[3]}$.

(3) Enriching knowledge background is important. Since the compilation of textbooks is restricted by publishing houses, many textbooks often deviate greatly from the knowledge of modern society. Therefore, in addition to teaching the content from the textbook, teachers also should absorb more information and knowledge beyond to increase students' enthusiasm for learning and consolidate knowledge points.

(4) Cultivate students 'self-confidence, thereby enhancing students' independent learning ability. For students, English learning has certain difficulties. (Therefore, students have the need to improve their English.) For the students who lack basic knowledge, they are unable to keep up with the progress of the course, and many students may lose their interest in learning English. Therefore, in English teaching, teachers need to formulate learning plans based on the actual situation of students, and actively encourage students. When students make 
progress, teachers should praise them in time to enhance their self-confidence. In curriculum planning and design, teachers should pay attention to the make every teaching level clear, and adjust the classroom teaching plan appropriately according to students' current English level. A good communication platform needs to be established between teachers to strengthen students' learning initiatives. It not only improves students' English level but also enhances their ability of independent exploration and innovation ${ }^{[3]}$.

\subsection{The Guiding Role of Applied Linguistics}

With the deepening of reforms and the current construction of education, teaching concepts and teaching modes have changed. Teachers are more inclined to pay attention to students' abilities in inquiring, thinking and innovating, and teaching design will also focus on students. It is no longer a fixed educational content. These changes in teaching concepts are consistent with the teaching theory of applied linguistics, so the role of applied linguistics in English teaching reform is salient.

Regarding the specific classroom teaching, Personally, I think that it can be developed from the following aspects. First, strengthen theoretical research on applied linguistics. Teachers should combine English teaching experience with good theoretical knowledge to guide the teaching reform. Second, deepen the research of applied linguistics, make every English teacher familiar with theoretical knowledge, and then carry out research activities related to teaching. It is necessary to give full play to the role of teachers in the reform of English teaching. Third, combine theory with classroom practice to develop listening, speaking, reading, writing, and translation skills, encourage students to take part in more practice activities in English class and expand students' international perspectives.

As the scope of education reform is so wide, we can not only seek change and innovation but also combine applied language theory with a practical education. We do not aim at superficial reforms but hope to help students improve their English. In addition, the main goal of higher education is to cultivate students' practical and innovative abilities, which should be studied according to the language knowledge mastered by students ${ }^{[5]}$.

Conclusion: Functional linguistics is mainly used in English teaching.

Functional linguistics has a huge impact on English teaching theory and practice. In English teaching, we should not only focus on the language form of English but also focus on explaining the actual functions of English to students, so that the form and function of English occupy an equal position in English teaching. Students gradually master English functions. With the continuous deepening of education reform, (teaching methods are gradually changing in order to cultivate students' self-learning management analysis and innovative ability?). The teaching methods of different disciplines are no longer limited to a single teaching method. The diversified classroom teaching model combined with rich classroom content ensures that different teaching concepts can be better absorbed by students, so as to improve teaching effects. The close connection between applied linguistics and English teaching can make English classroom teaching more artistic and scientific. Therefore, it is very important to understand how to use applied linguistic theory to guide English teaching reform. This paper briefly explains this, and more educators are urgently needed to keep analyzing and exploring.

\section{References}

[1] Feng Xiangping. The Application of Cohesion and Coherence in the Teaching of English Writing Based on the Theory of Theme-Rheme Theory of Systematic Functional Linguistics [J]. Journal of Shazhou Professional Institute of Technology, 2017(04): 54-57.

[2] Zhong Weizheng, Li Pei. Application of Systematic Functional Linguistics in English Teaching in Higher Vocational Colleges [J]. High School Years, 2017(26): 218-219.

[3] Wang Xinping. Application of Systematic Functional Linguistics in College Oral English Teaching [J]. Journal of Hunan City University (Natural Science Edition), 2016(05): 309-310.

[4] Li Pei, Qiu Jie, Jiang Ruihong. Applied Research of Systematic Functional Linguistics in College English Writing Teaching [J]. Overseas English, 2016 (06): 170-171.

[5] Xia Lifang. The Application of Context Theory of Systematic Functional Linguistics in College English Teaching [J]. Asia- Pacific Education, 2015 (33): 104. 